\title{
Fenton pre-treated microfibrillated cellulose evaluated as a strength enhancer in the middle ply of paperboard
}

\author{
Pia Hellström, Anette Heijnesson-Hultén, Magnus Paulsson, Helena Håkansson and Ulf Germgård
}

KEYWORDS: Microfibrillated cellulose, Fenton's reagent, Enzymatic hydrolysis, Tensile strength, Zdirectional strength, Bending stiffness index, Bending resistance, Dewatering

SUMMARY: Microfibrillated celluloses (MFCs), produced by various pre-treatments of a fully bleached birch kraft pulp, were evaluated as strength enhancers in test sheets representing the middle ply of paperboard. The furnish consisted of hydrogen peroxide bleached high temperature spruce chemithermomechanical pulp (HTCTMP), MFC and a retention system containing cationic starch and an anionic silica sol. The MFC was prepared via a mechanical treatment in a colloid mill after pretreatment with Fenton's reagent, monocomponent endoglucanase or acidic hydrogen peroxide. Addition of 5\% MFC, produced with Fenton pre-treatment, resulted in improved HT-CTMP properties with respect to increased tensile index ( 35\%), z-directional strength ( $\sim 50 \%)$, tensile stiffness index ( 25\%) compared to HTCTMP test sheets prepared without MFC addition. The strength improvement was linearly correlated to the density of the tests sheet, to the surface area (BET) and to the surface charge of the enzymatic or chemically pretreated MFCs.

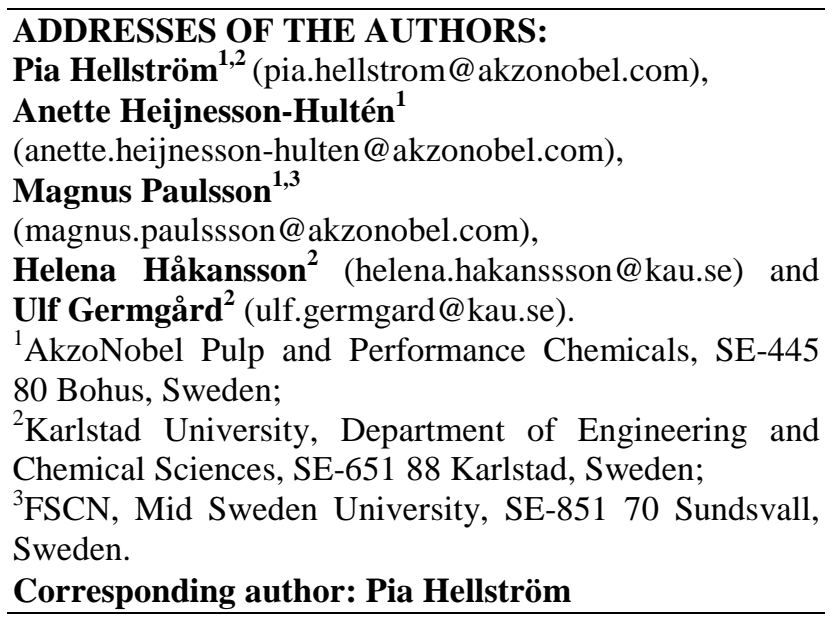

During the last decades there has been an increasing interest in the pulp and paper industry to use lignocellulosic materials for production of micro- and nanofibrillated cellulose (MFC and NFC) (Österberg, Cranston 2014). The aim is to improve existing products as well as to create new products and develop new application areas (Sandquist 2013). A variety of important industrial uses for MFC/NFC have been suggested, such as rheology modifier in foods and paints, as reinforcement in composites, as strength enhancer in papers and in barriers with low permeability to gases (Turbak et al. 1983; Zimmermann et al. 2004; Henriksson et al. 2007; Eriksen et al. 2008; Syverud, Stenius 2009). MFC was first produced by Turbak et al. (1983) by intense mechanical treatment of wood fibres by several passes through a pressurized homogenizer. The MFC production is accompanied with a high energy demand that has to be reduced to facilitate industrial production. Thus, several pre-treatment methods have been proposed to overcome this obstacle: enzymatic (Henriksson et al. 2005; Pääkkö et al. 2007), and chemical such as carboxymethylation (Henriksson et al. 2007; Bhandari et al. 2012) or TEMPO-mediated oxidation (TEMPO = 2,2,6,6-tetramethylpiperidine-1-oxyl) (Isogai, Kato 1998; Iwamoto et al. 2010; Isogai et al. 2011). The use of Fenton's reagent i.e. treatment with acidic hydrogen peroxide in the presence of ferrous ions producing hydroxyl radicals has also been suggested (HeijnessonHultén 2005).

The morphology and chemistry of MFC/NFC products vary significantly depending on the source of raw material and the production method used. Without chemical or enzymatic pre-treatments or fractionation, MFC products generally consist of a mixture of unaffected fibres, fibre fragments and small sized fibrils i.e. have a broad size distribution (Chinga-Carrasco 2011; Lavoine et al. 2012). In contrast, MFC produced by TEMPO-mediated oxidation, combined with mechanical treatment consist of smaller and more uniform microfibrils with a high charge density (Isogai et al. 2011).

The mechanical properties of a paper product are related to the individual fibre strength, the bonding strength per unit area and the bonded area of the fibres. One of the most commonly used methods to increase the connectivity of cellulose fibres within a paper network is by beating. During beating, the fibres are made more flexible and can easier conform to each other's surfaces. The mechanical properties of paper products are also known to be improved by addition of fines (Aaltio 1962; Retulainen et al. 1993; Retulainen and Nieminen 1996; Bäckström et al. 2008). For example, addition of fines to long fibre fraction of a bleached softwood kraft pulp increased the tensile index with $47 \%$ at a fines content of 6\% (Retulainen and Nieminen 1996).

The strength of paper can also be improved by increasing the number of bonds between the fibres by adding dry strength additives like starch or carboxymethylcellulose, often together with a drainage improving additive like cationic polyacrylamide.

The benefits of using MFC/NFC as strength enhancers in paper applications have during the last years been explored by several researchers (Ahola et al. 2008; Eriksen et al. 2008; Mörseburg, Chinga-Carrasco 2009; Taipale et al. 2010; González et al. 2012; Joseleau et al. 2012; Kajanto, Kosonen 2012; Zhang et al. 2012). Da Silva Perez et al. (2010) demonstrated a clear relationship between the MFC/NFC quality and the reinforcement effect in paper sheets prepared from both softwood and hardwood pulps. The MFC with the smallest particles and 
the most homogenous particle size distribution gained the largest improvement in tensile and tear properties. At an addition level of $5 \%$ of MFC/NFC, the improvement was $20-25 \%$ in both tensile- and tear index compared with sheets prepared without addition of MFC/NFC. These results are consistent with an earlier study made by Eriksen et al. (2008) who evaluated the addition of MFCs with different average fibril sizes to hand sheets prepared from thermomechanical pulp. The study revealed an increased tensile index when the average fibril size of the MFC decreased. Osong et al. (2014) produced NFC from bleached kraft pulp fines and chemithermomechanical pulp (CTMP) fines by mechanical treatment in a homogeniser. The produced NFC's were blended with bleached kraft pulp and CTMP pulp and the strength properties were evaluated on hand sheets. At an addition level of 5\% NFC the strength improvement were moderate, $5-10 \%$ in z-strength and not significant for tensile index and bending stiffness when compared with sheets without addition of NFC.

Due to their large specific surface area and high aspect ratio, MFC/NFC exhibits a high water retention capacity, a property that can be desirable or undesirable depending of the field of application. In paper making, it is an advantage to enhance the paper properties without simultaneously deteriorate the drainage properties and thereby the efficiency of the paper machine. The introduction of more fibrillated materials like MFC may affect the drainage negatively (Taipale et al. 2010; Collin et al. 2012; Afra et al. 2013; Djafari Petroudy et al. 2014). However, Taipale et al. (2010) demonstrated an improvement in tensile index and Scott bond with 25\% and $70 \%$ respectively, without deteriorating the drainage time by selection of suitable MFC and process conditions.

The aim of this work is to evaluate the effect of MFC products produced from a fully bleached birch kraft pulp as strength enhancers in test sheets of high temperature chemimechanical pulp representing the middle ply of paperboard and to correlate the results obtained to morphological and chemical characteristics of the MFCs determined in an earlier study (Hellström et al. 2014). The MFC's were prepared without or with (enzymatic, Fenton, acid) pre-treatment followed by mechanical processing in a colloid mill.

\section{Materials and Methods}

\section{Preparation of MFC products}

The MFC products were prepared from a fully bleached birch (Betula verucosa) kraft pulp with the following properties: ISO brightness $88.6 \%$, kappa number 0.62 and intrinsic viscosity $929 \mathrm{dm}^{3} / \mathrm{kg}$. Birch fibres have proved to give MFC with good quality and with its relatively short fibre length will reduce the risk for clogging of the equipment (Tapin-Lingua 2013).The kraft pulp was pretreated with acidic hydrogen peroxide in the presence of ferrous ions (i.e. Fenton's reagent) in two addition levels of hydrogen peroxide, 10 and $50 \mathrm{~kg} / \mathrm{t}$, hereafter denoted Fenton Low and Fenton High. For comparison an enzymatic pre-treatment was performed using a
Table 1 - The conditions employed for the chemical and enzymatic pre-treatments. The data are taken from Hellström et al. (2014)

\begin{tabular}{|c|c|c|c|c|c|}
\hline \multirow{2}{*}{ Conditions } & \multirow{2}{*}{$\begin{array}{c}\text { Acid } \\
\text { Peroxide }\end{array}$} & \multicolumn{2}{|c|}{ Fenton } & \multicolumn{2}{|c|}{ Enzyme } \\
\hline & & Low & High & Low & High \\
\hline $\mathrm{H}_{2} \mathrm{O}_{2}, \mathrm{~kg} / \mathrm{t}$ & 10 & 10 & 50 & & \\
\hline $\mathrm{Fe}^{2+}, \mathrm{kg} / \mathrm{t}$ & & 0.04 & 0.20 & & \\
\hline $\mathrm{H}_{2} \mathrm{SO}_{4}, \mathrm{~kg} / \mathrm{t}$ & 0.6 & 0.5 & 0.3 & & \\
\hline $\mathrm{pH}_{\text {start }}$ & 3.5 & & .5 & & .0 \\
\hline $\begin{array}{l}\text { FiberCare }^{\circledR} \mathrm{R}, \\
\mathrm{ECU} / \mathrm{g}\end{array}$ & & & & 1.0 & 2.0 \\
\hline Consistency, \% & 10 & & 0 & & 4 \\
\hline Time, min. & 150 & & 50 & & 20 \\
\hline Temp., ${ }^{\circ} \mathrm{C}$ & 90 & & 0 & & 50 \\
\hline
\end{tabular}

monocomponent endoglucanase (FiberCare ${ }^{\circledR} \mathrm{R}$, Novozymes AS, Denmark), charged at one respectively two endocellulase units (ECU) per mass unit of material, Enzyme Low and Enzyme High. Additionally, the pulp was treated at the conditions used in the Fenton pretreatments without charge of iron representing the reference denoted Acid Peroxide. The chemical charges and conditions during the pre-treatments can be seen in Table 1. The pulps were thereafter mechanically treated in a colloid mill, IKA magic LAB equipped with module MK for 0, 10, 30 and 53 min. The preparation methodology and characterization of the MFC products are described in detail in a previously published study (Hellström et al. 2014).

\section{Sheet preparation and analysis}

Test sheets representing the middle ply in paperboard, with a target basis weight of $120 \mathrm{~g} / \mathrm{m}^{2}$, were produced from a hydrogen peroxide bleached Norway spruce (Picea abies) high temperature chemithermomechanical pulp (HT-CTMP). The pulp had a Canadian Standard Freeness of $700 \mathrm{~mL}$ and a brightness of $70 \%$ ISO. After hot disintegration according to ISO 5263:1995, the HTCTMP was diluted to $0.5 \% \mathrm{w} / \mathrm{w}$ and $\mathrm{CaCl}_{2}$ (Fischer Chemicals) was added to a concentration of $0.1 \mathrm{~g} / \mathrm{L}$. The conductivity was thereafter adjusted to $1200 \mu \mathrm{S} / \mathrm{cm}$ with sodium sulphate (Scarlau Chemie). Sheets were formed in a dynamic sheet former (DSF), Techpap supplied by Centre Technique du Papier, France, by pumping the fibre furnish from the mixing chest through a transversing nozzle into the rotation drum. In order to avoid losses of fines and MFC upon sheet making, a retention system consisting of cationic potato starch, SolBond C50 from Lyckeby, Sweden and anionic silica sol, NP 442 from AkzoNobel, Sweden was used. When MFC was charged, the amount of HT-CTMP fibres was reduced to maintain the target basis weight of the test sheets. Basis weights were used as an indirect measure of the MFC retention during sheet formation. The chemical charges used and the order of addition are presented in Table 2.

The DSF sheets were cut into smaller sheets $(260 \times 220$ $\mathrm{mm}$ ) and pressed between three blotters at 10 bars in a plane press for $10 \mathrm{~min}$ and thereafter dried restrained in a plane dryer from STFI, Sweden $\left(105^{\circ} \mathrm{C}, 10 \mathrm{~min}\right)$. 
Table 2 - Chemical charges and addition order for the chemicals used in the stock preparation.

\begin{tabular}{lccc}
\hline Chemical & MFC product & Cationic starch & Silica sol \\
\hline Charge, \% & 5.0 & 1.0 & 0.3 \\
Added at time, s & 0 & 30 & 45 \\
\hline
\end{tabular}

All sheets were conditioned prior to testing in a climate room at $23^{\circ} \mathrm{C}$ and $53 \%$ relative humidity according to ISO 187:1999. Thickness, grammage, tensile strength and stiffness, z-directional strength and bending resistance index were determined according to ISO 534:2005, ISO 536:1995, ISO 1924-3:2005, SCAN-P 80:98 and SCANP 29:95, respectively. Since the dynamic sheet former produces anisotropic sheets the tensile properties are reported as geometrical mean values. For the drainage tests, a dynamic drainage analyser (DDA) from Eurocon, Sweden was used at 1500 rpm stirrer speed and -150 mbar. The furnish composition, chemical charges and order of addition were the same as during the sheet preparation, Table 2. The 95\% confidence interval for tensile index and tensile index stiffness are based on geometrical mean values for 5 measurements in the machine direction and 5 measurements in the cross direction. Calculation of the confidence interval for bending resistance index is made from 16 separate measurements. For $\mathrm{z}$-directional strength the $95 \%$ confidence interval was determined by calculation of the pooled standard deviation for each pre-treatment method i.e. 5 samples performed in triplets.

\section{Results and Discussion}

There is no common and accepted defined size distribution of a product to be named MFC, although an ISO standardisation group is working on an international classification (SIS-CEN ISO/TS 27687:2009). According to some researchers, in a properly produced MFC the main part of the cellulose components should have a diameter of $100 \mathrm{~nm}$ or less (Chinga-Carrasco 2011; Abdul Khalil et al. 2012). The products evaluated in this study contained varied portions of fibres, fibre fragments, fibrils and microfibrils in varied amounts (Hellström et al. 2014). A schematic description of the total experimental layout can be seen in Fig 1, Part 1 represents the preparation and characterisation of the MFC products described in Hellström et al. (2014). The outline for Part 2, which is this paper, is an evaluation of

Part 1

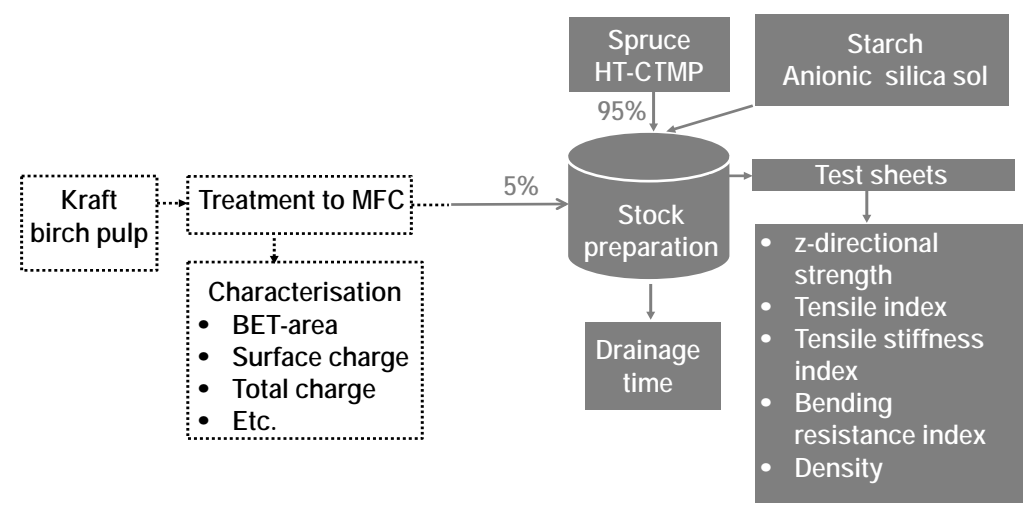

Fig 1 - Schematic description of the experimental layout. Part 1 is from Hellström et al. (2014) and Part 2 is this study. representing the middle ply of a paper board.

\section{The characteristics of the MFC products} $100 \mathrm{dm}^{3} / \mathrm{kg}$.

\section{Strength properties} 2005).

\section{Part 2}

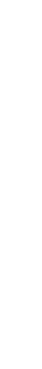

the MFC products as strength enhancers in test sheets

The main characteristics of the MFCs are summarized in Table 3. As can be seen the MFCs prepared with Fenton pre-treatment had a higher specific surface area measured as Brunauer-Emmett-Teller (BET) area and a higher surface charge at a given mechanical treatment time in the colloid mill compared to MFC products produced without pre-treatment or pre-treated with acidic hydrogen peroxide or enzymes. It is also seen that Fenton pretreatment significantly reduced the intrinsic viscosity of the pulps. Further, fractionation and scanning electron microscopy studies revealed that Fenton pre-treatment gave a MFC product that contained a higher amount of small well fibrillated particles compared to the enzymatic and acid pre-treatment methods. The enzymatic hydrolysis, as performed in this study, increased the specific surface area as a function of mechanical treatment time comparable to a pulp without any pretreatment. Further, the total charge was not substantially altered and the intrinsic viscosity decreased by less than

A paperboard is commonly constructed in several plies with strong outer plies produced from chemical pulp fibres and a bulky middle ply produced from mechanical or chemimechanical pulp fibres. CTMP and HT-CTMP are often used in the middle layer due to their capacity to create high bulk and high bending stiffness (Höglund 2002). However, mechanical pulps produced with high temperature processes (e.g. HT-CTMP) contain long and stiff fibres covered with lignin which generally affect the bonding ability negatively (Pynnönen et al. 2005; Klinga et al. 2008). In this respect, the optimal properties for the middle ply layer of board are bulk high enough for the required bending stiffness, and internal bond strength high enough to avoid board delamination (Klinga et al. 
Table 3 - Main characteristics for MFC products produced from untreated, chemically or enzymatically pre-treated birch kraft pulps mechanically processed for 0, 10, 30 and $53 \mathrm{~min}$ in a colloid mill. The data are taken from Hellström et al. (2014)

\begin{tabular}{|c|c|c|c|c|c|c|c|}
\hline Analysis & $\begin{array}{l}\text { Mechanical treatment time, } \\
\text { min }\end{array}$ & $\begin{array}{l}\text { No pre- } \\
\text { treatment }\end{array}$ & $\begin{array}{c}\text { Acid } \\
\text { Peroxide }\end{array}$ & $\begin{array}{l}\text { Fenton } \\
\text { Low }\end{array}$ & $\begin{array}{l}\text { Fenton } \\
\text { High }\end{array}$ & $\begin{array}{l}\text { Enzyme } \\
\text { Low }\end{array}$ & $\begin{array}{c}\text { Enzyme } \\
\text { High }\end{array}$ \\
\hline \multirow{4}{*}{$\begin{array}{l}\text { BET-area, } \\
\mathrm{m}^{2} / \mathrm{g}\end{array}$} & 0 & 2 & 2 & & 2 & & 2 \\
\hline & 10 & 4 & 4 & & 6 & & 4 \\
\hline & 30 & 5 & 7 & & 8 & & 5 \\
\hline & 53 & 7 & 9 & & 10 & & 6 \\
\hline \multirow{4}{*}{$\begin{array}{l}\text { Surface charge, } \\
\mu \mathrm{eq} / \mathrm{g}\end{array}$} & 0 & 2 & & 5 & 6 & & 7 \\
\hline & 10 & 18 & & 26 & 36 & & 17 \\
\hline & 30 & 23 & & 40 & 44 & & 28 \\
\hline & 53 & 30 & & 53 & 54 & & 38 \\
\hline $\begin{array}{l}\text { Total charge, } \\
\mu \text { eq/g }\end{array}$ & 0 & 41 & 38 & 45 & 58 & & 42 \\
\hline \multirow{4}{*}{$\begin{array}{l}\text { Intrinsic } \\
\text { viscosity, } \\
\mathrm{dm}^{3} / \mathrm{kg}\end{array}$} & 0 & 929 & 445 & 282 & 186 & 843 & 844 \\
\hline & 10 & 869 & 442 & 273 & 182 & 801 & 790 \\
\hline & 30 & 884 & 426 & 268 & 178 & 807 & 793 \\
\hline & 53 & 868 & 425 & 267 & 178 & 814 & 709 \\
\hline
\end{tabular}

\section{Strength properties}

A paperboard is commonly constructed in several plies with strong outer plies produced from chemical pulp fibres and a bulky middle ply produced from mechanical or chemimechanical pulp fibres. CTMP and HT-CTMP are often used in the middle layer due to their capacity to create high bulk and high bending stiffness (Höglund 2002). However, mechanical pulps produced with high temperature processes (e.g. HT-CTMP) contain long and stiff fibres covered with lignin which generally affect the bonding ability negatively (Pynnönen et al. 2005; Klinga et al. 2008). In this respect, the optimal properties for the middle ply layer of board are bulk high enough for the required bending stiffness, and internal bond strength high enough to avoid board delamination (Klinga et al. 2005).

As can be seen in Fig 2 A-C the z-directional strength, tensile index and tensile stiffness index increased for HTCTMP test sheets that had been reinforced with the MFCs as described earlier. In general, sheets with MFC pre-treated with Fenton's regent and enzymatic hydrolysis demonstrated a higher increase in strength properties compared to MFC prepared with acidic hydrogen peroxide or without pre-treatment. Fenton pretreated MFCs improved the strength properties the most; the z-directional strength increased by about $50 \%$, the tensile index with about $35 \%$ and the bending stiffness index with over $20 \%$. Worth noting is the marginal difference in strength development for MFC produced with $50 \mathrm{~kg} \mathrm{H}_{2} \mathrm{O}_{2}$ /ton (Fenton High) and $10 \mathrm{~kg} \mathrm{H}_{2} \mathrm{O}_{2}$ /ton (Fenton Low) respectively indicating a possibility to reduce the hydrogen peroxide charge in the pre-treatment. Further, the change in bending resistance index is mostly within the experimental error and are slightly lower or not affected at all by the mechanical processing time (Fig 2D).

The levelling off in strength properties after about 30 min of mechanical treatment time probably was due to limitations in the mechanical equipment used for producing the MFCs. This assumption was based on the knowledge that the MFC products used in this study still after 53 min of mechanical processing contained a substantial amount of larger fiber fragments (Hellström et al. 2014). The improvement in strength properties were linearly proportional to sheet densities for all pretreatments evaluated, an expected and well known relationship (Fredriksson, Höglund 1978; Rundlöf 2002). The same correlations were obtained for strength properties and surface charge (Fig $3 A-D)$ and for strength properties and BET-area (Fig 4A-D). Deviations in both sheet preparation and furnish composition makes it difficult to compare the result obtained in this investigation with earlier published findings. However, Taipale et al. (2010) reported a 60\% increase in Scott bond and $8 \%$ increase in tensile index when 5\% MFC were charged to a bleached softwood kraft pulp furnish containing $1.5 \%$ cationic starch. Da Silva Perez et al. (2010) reported a tensile index increase of 20-25\% when 5\% MFC was added to hardwood and softwood kraft pulp furnishes and Osong et al. (2014) received 5-10\% increase in z-directional strength and an insignificant increase in tensile index at 5\% NFC addition level.

The strength improvement as a consequence of MFC addition is most likely due to an increased number of bonds between the stiff HT-CTMP fibers where the MFC act as a binding phase in between. In this respect a high surface area (BET) of the MFC is of importance. The MFC produced with Fenton pre-treatment have higher specific surface area and thereby a higher surface charge at a given mechanical treatment time compared to enzymatic pre-treated MFCs which indicates a possibility to reduce the energy consumption during the production of microfibrillated cellulose. The hydroxyl radicals formed in the Fenton reaction react with the cellulosic material under the formation of alkyl and carbon radicals and can lead to the opening of the anhydroglucose ring or a breakage of the cellulose chain. In both cases carbonyl groups are formed which can be further oxidised to carboxyl groups (Henniges et al. 2012; Pouyet et al. 2014). Endoglucanases are generally considered to randomly attack accessible intramolecular $\beta-1,4-$ glucosidic bonds in the middle of the cellulose chain and will generate oligomers of different sizes and new 
reducing end groups. As a consequence, the intrinsic viscosity of the pulp fibres will decrease and the carbonyl content increase. However, the pre-treatment with endoglucanase as performed in this study resulted in a
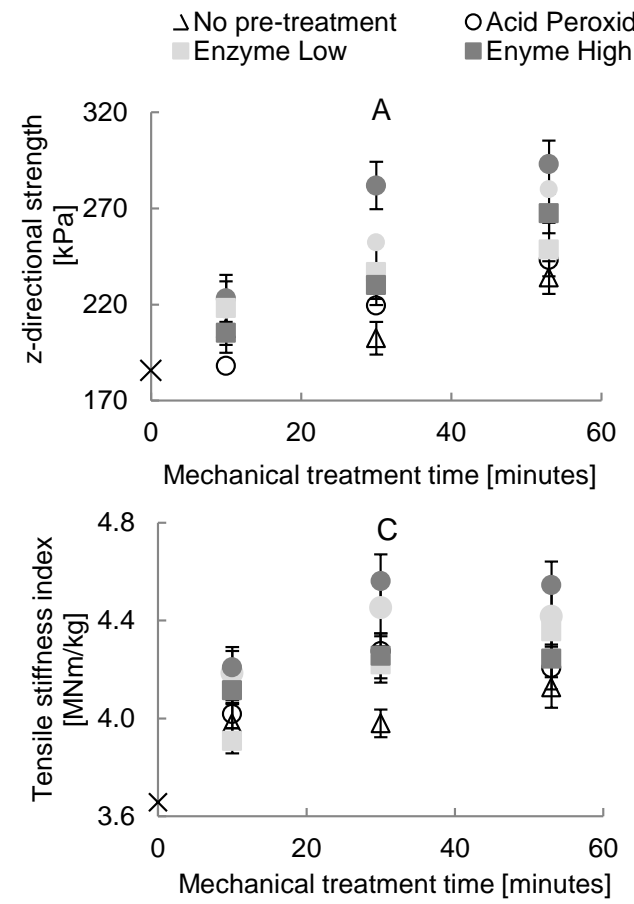

moderate decrease in intrinsic viscosity $\left(85 \mathrm{dm}^{3} / \mathrm{kg}\right)$ without increasing the amount of carbonyl groups (Hellström et al. 2014). This indicates a mild enzymatic hydrolysis and less impact on the cellulosic material compared to the MFCs produced with Fenton pretreatment.

Fenton Low Fenton High $\times$ Without MFC
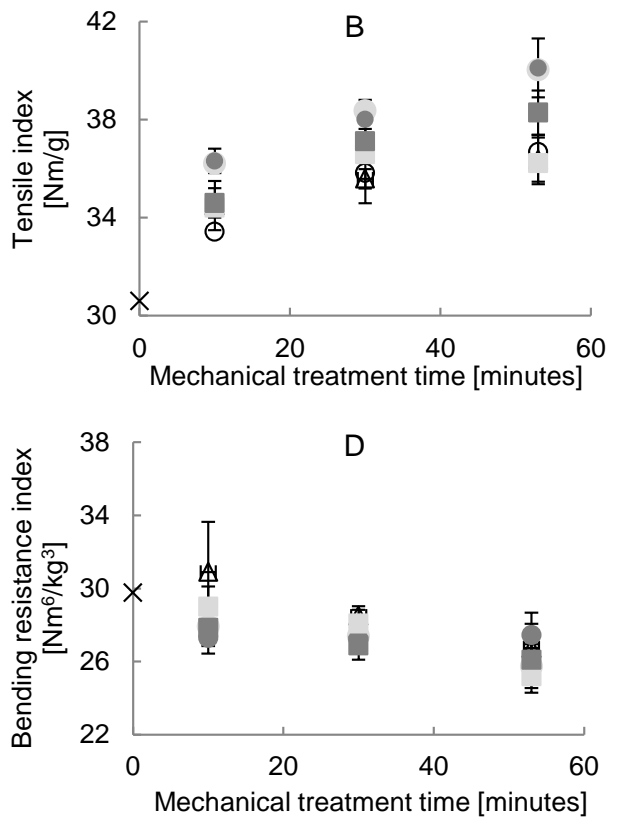

Fig 2 - Z-directional strength $(A)$, tensile index (B), tensile stiffness index (C) and bending resistance index (D) for test sheets produced with MFC prepared without pre-treatment (No pre-treatment) as well as pre-treatment with acidic hydrogen peroxide (Acid Peroxide), Fenton's reagent (Fenton Low and Fenton High) and enzymatic hydrolysis (Enzyme Low and Enzyme High) are in the graphs shown as a function of the mechanical treatment time in the colloid mill when producing the MFC. 95\% confidence intervals are given for No pre-treatment, Fenton High and Enzyme High.

$\Delta$ No pre-treatment
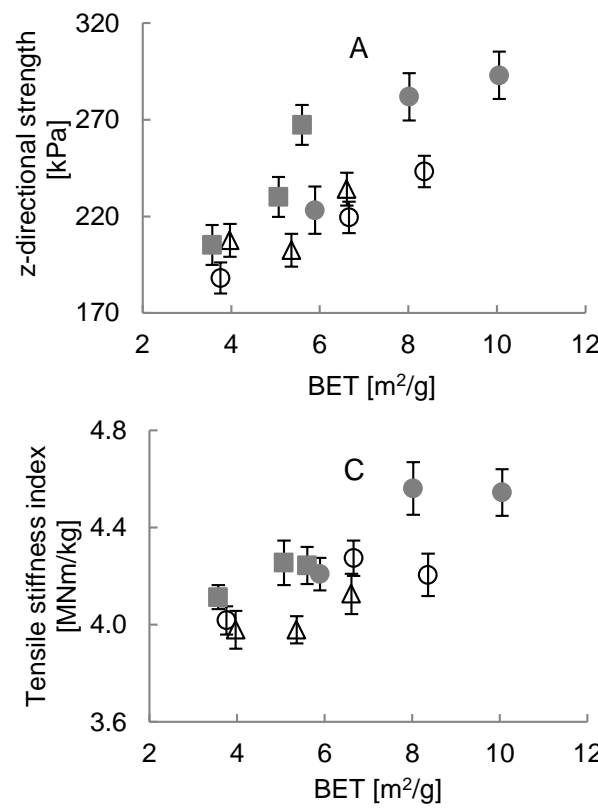

- Fenton High

Enyme High
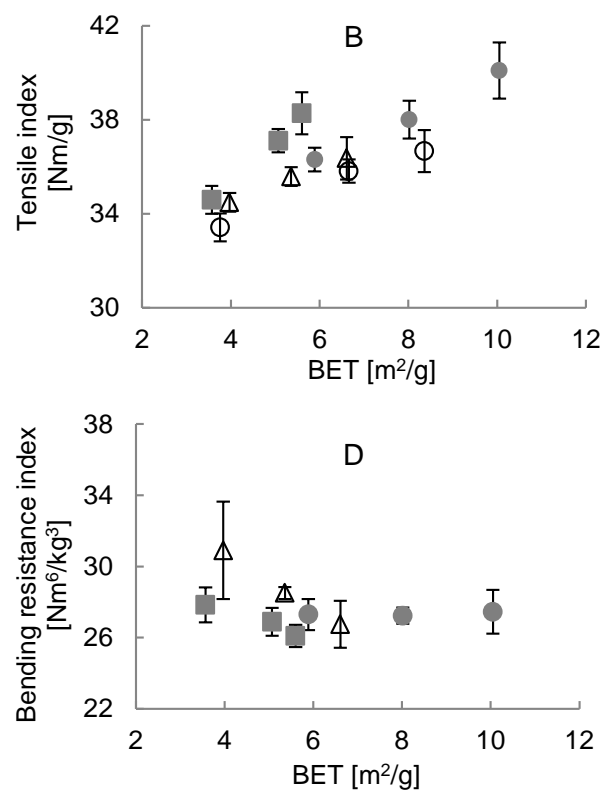

Fig 3 - Z-directional strength $(A)$, tensile index (B), tensile stiffness index (C) and bending resistance index (D) for test sheets produced with MFC prepared without pre-treatment (No pre-treatment) as well as pre-treatment with acidic hydrogen peroxide (Acid Peroxide), Fenton's reagent (Fenton High) and enzymatic hydrolysis (Enzyme High) are in the graphs shown as a function specific surface area (BET). Error bars show the 95\% confidence interval. 

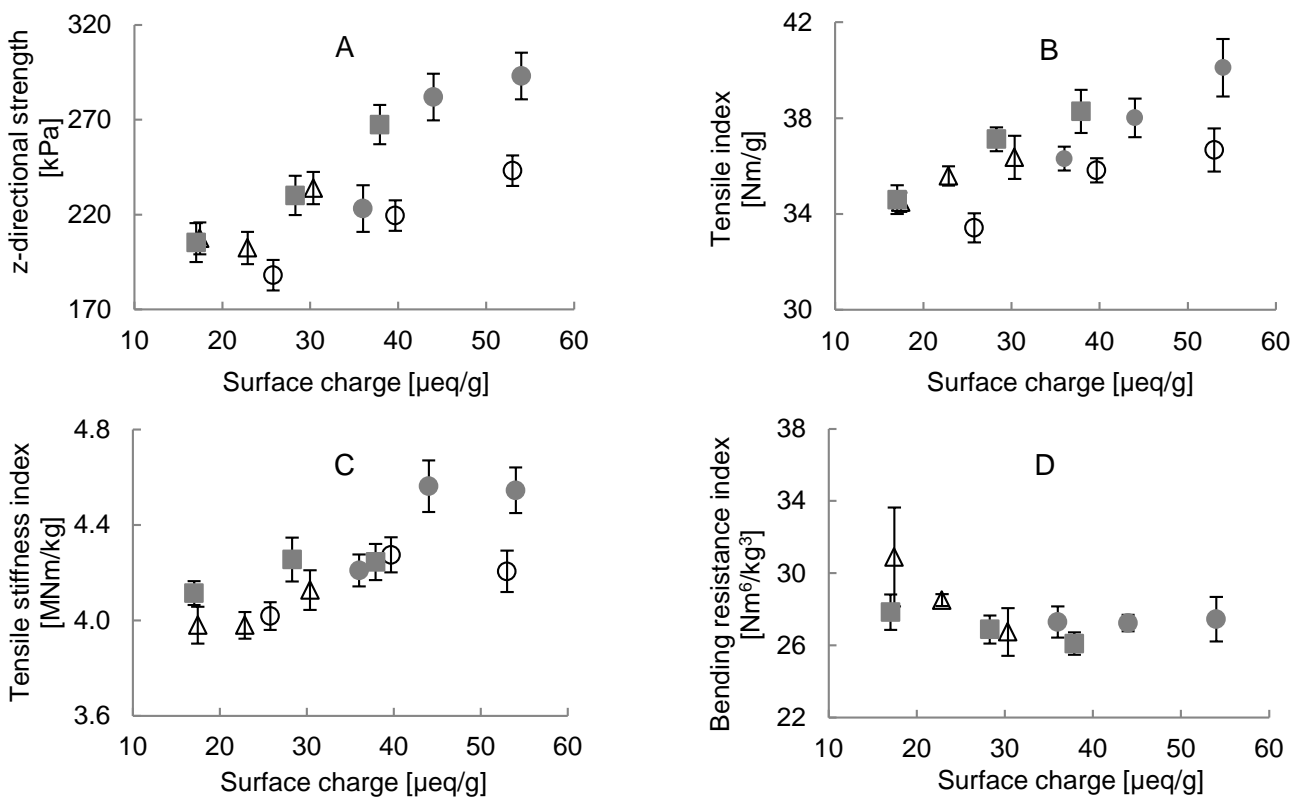

Fig 4 - Z-directional strength (A), tensile index (B), tensile stiffness index (C) and bending resistance index (D) for test sheets produced with MFC prepared without pre-treatment (No pre-treatment) as well as pre-treatment with acidic hydrogen peroxide (Acid Peroxide), Fenton's reagent (Fenton High) and enzymatic hydrolysis (Enzyme High) are in the graphs shown as a function specific surface area (BET). Error bars show the $95 \%$ confidence interval.
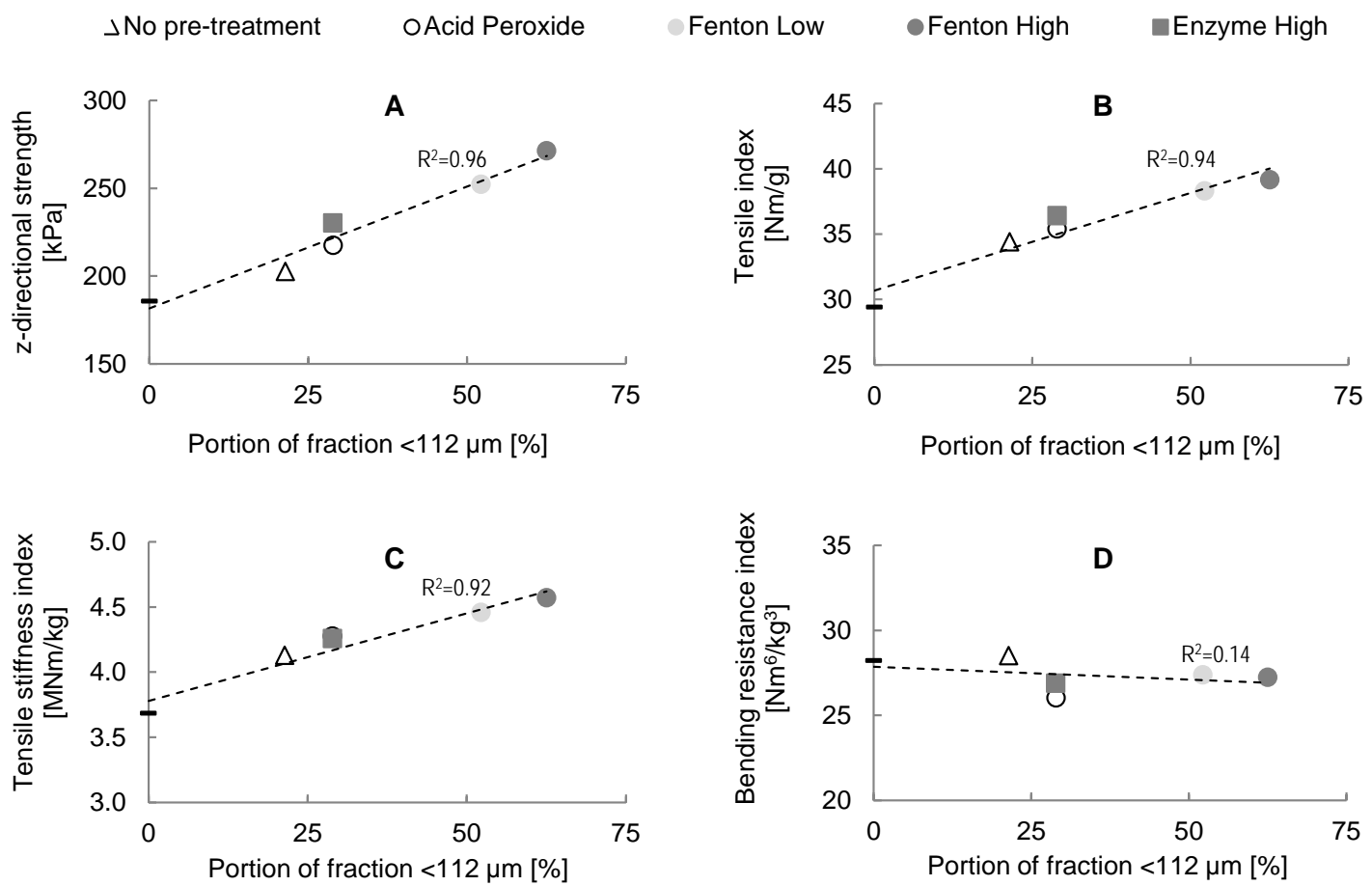

Fig 3 - Z-directional strength (A), tensile index (B), tensile stiffness index (C) and bending resistance index (D) for test sheets prepared with and without MFC (5\%) as a function of the weight in percent of the MFC products that passes through a $112 \mu \mathrm{m}$ nylon net. The MFCs were prepared without pre-treatment (No pre-treatment), pre-treatment with acidic hydrogen peroxide without addition of ferrous ions (Acidic Peroxide), Fenton's reagent (Fenton Low and Fenton High) and enzymatic hydrolysis (Enzyme High) followed by mechanical treatment in a colloid mill for $30 \mathrm{~min}$. 


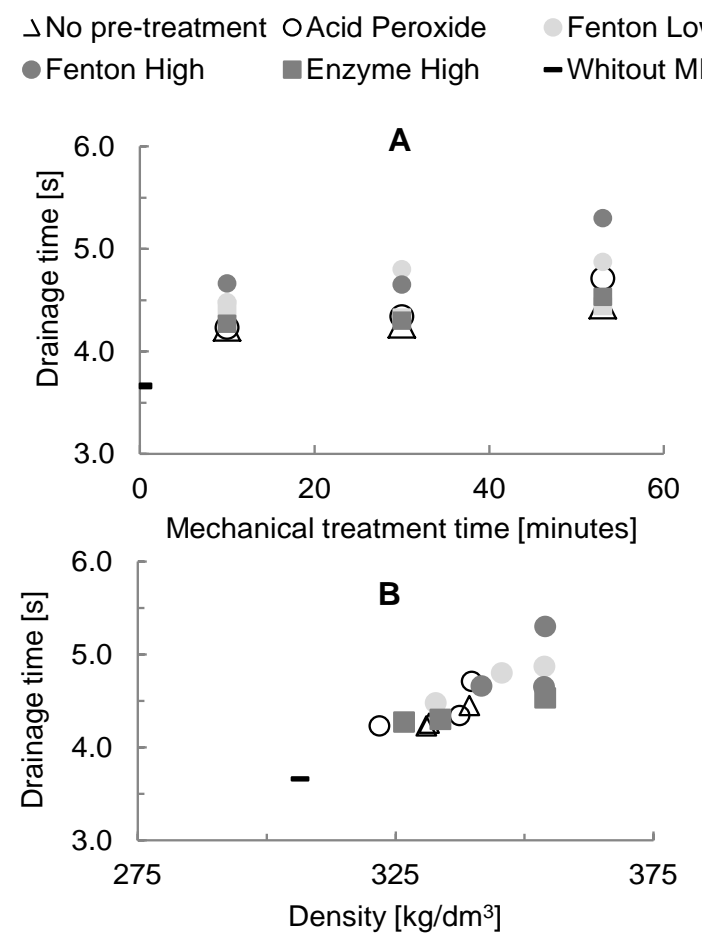

Fig 4 - Drainage time as a function of mechanical processing time in a colloid mill during the preparation of MFC (A) and drainage time as a function of sheet density $(B)$.

There is a clear linear correlation between the weight in percent of the MFC products that passes $112 \mu$ mylon net and the z-directional strength, tensile index and tensile stiffness index, Fig 3 A-C. The bending resistance index is not affected by the amount of material within this fraction, Fig 3D. For sheets prepared without MFC, the fraction $<112 \mu \mathrm{m}$ are considered to be zero since no small sized particles have been added. Provided uniformity in starting material and mechanical equipment when preparing the MFC, the coarse fractionation may be used for a simple and quick evaluation of the MFC as a strength enhancer in papermaking.

\section{Dewatering}

The drainage properties were measured with a DDA equipment using the furnish composition, chemical charges and addition order of chemicals as during the sheet preparation, see Table 2. The drainage time was increased with $20-45 \%$ (Fig $4 A$ ) by the addition of the differently prepared MFCs and was linearly correlated to the sheet density (Fig 4B) and BET-area of the MFCs (data not shown). The magnitude of the dewatering impairment are hard to compare with results presented by other researchers since it is highly dependent on the origin and beating degree of the pulp used in the furnish as well as the properties of the MFC and of the used retention system. However, Taipale et al. (2010) have shown that it is possible to improve the strength properties without deterioating the draingage by selection of approperiate MFC and process conditions.

\section{Conclusions}

Microfibrillated cellulose (MFC) prepared from a fully bleached birch kraft pulp by either mechanical treatment alone or by Fenton or enzymatic pre-treatments followed by a mechanical treatment in a colloid mill were added to a high-temperature, hydrogen peroxide bleached chemithermomechanical pulp (HT-CTMP) furnish. The pulp strength properties were assessed on test sheets formed in a dynamic sheet former. From the results it could be concluded that:

-Fenton pre-treatment resulted in MFC that when added to a HT-CTMP furnish increased the strength properties more compared to MFCs produced with monocomponent endoglucanase pre-treatment. Addition of 5\% Fenton pretreated MFC resulted in an increase in z-directional strength of about $50 \%$, an increase in tensile stiffness index of about $25 \%$ and an increase in tensile index of 35\% compared to HT-CTMP test sheets prepared without MFC addition.

-The improvement in strength properties was proportional to sheet density, to the surface area (BET) and to the surface charge of the MFC

-The strength improvement as a consequence of MFC addition is most likely due to an increased number of bonds between the stiff HT-CTMP fibres where the MFC act as a binding phase in between.

-The amount of MFC particles smaller than $112 \mu \mathrm{m}$ correlates well with measured paper board strength properties.

-The drainage time increased with $20-45 \%$ by addition of the differently prepared MFCs and was linearly correlated to the sheet density and to the surface area of the MFCs.

\section{Acknowledgements}

This study was performed as a part of the multidisciplinary Industrial Graduate School VIPP - Values Created in Fibre Based Processes and Products at Karlstad University, Sweden with the financial support from the Knowledge Foundation, Sweden.

\section{Literature}

Aaltio, E. (1962): The effect of highly beaten birch pulp fraction on the properties of kraft paper, Paperi Puu 44(4a), 217-222.

Abdul Khalil, H. P. S., Bhat, A. H. and Ireana Yusra, A. F. (2012): Green composites from sustainable cellulose nanofibrils: A review, Carbohydr Polym, 87, (2), 963-979.

Afra, E., Yousefi, H., Hadilam, M. M. and Nishino, T. (2013): Comparative effect of mechanical beating and nanofibrillation of cellulose on paper properties made from bagasse and softwood pulps, Carbohydr. Polym. 97(2), 725-730.

Ahola, S., Österberg, M. and Laine, J. (2008): Cellulose nanofibrils - adsorption with poly(amideamine) epichlorohydrin studied by QCM-D and application as a paper strength additive, Cellulose 15(2), 303-314.

Bhandari, P. N., Jones, D. D. and Hanna, M. A. (2012): Carboxymethylation of cellulose using reactive extrusion, Carbohydr. Polym. 87(3), 2246-2254.

Bäckström, M., Kolar, M.-C. and Htun, M. (2008): Charaterisation of fines from unbleached kraft pulps and their impact on sheet properties, Holzforschung 62(5), 546-552. 
Chinga-Carrasco, G. (2011): Cellulose fibres, nanofibril and microfibrils: The morphological sequence of MFC components from a plant physiology and fibre technology point of view, Nanoscale Res. Lett. 6(417), 1-7.

Collin, H., Gregrersen, Ø., Chinga-Carrasco, G. and Eriksen, $\emptyset$. (2012): The effect of MFC on the pressability and paper properties of TMP and GCC based sheets, Nord. Pulp Paper Res. J. 27(2), 388-396.

Da Silva Perez, D., Tapin-Lingua, S., Lavalette, A., Barbosa, T., Gonzalez, I., Siqueira, G., Bras, J. and Dufresne, A. (2010): Impact of micro/nanofibrillated cellulose preparation on the reinforcement properties of paper and composites films, Int. Conf. Nanotechnol. Forest Prod. Ind., Espoo, Finland, September 26-29, TAPPI Press, Norcross, GA, pp 1-20.

Djafari Petroudy, S. R., Syverud, K., Chinga-Carrasco, G., Ghasemain, A. and Resalati, H. (2014): Effects of bagasse microfibrillated cellulose and cationic polyacrylamide on key properties of bagasse paper, Carbohydr. Polym. 99(1), 311318.

Eriksen, Ø., Syverud, K. and Gregersen, Ø. (2008): The use of microfibrillated cellulose produced from kraft pulp as strength enhancer in TMP paper, Nord. Pulp Paper Res. J. 23(3), 299303.

Fredriksson, B. and Höglund, H. (1978): Chemithermomechanical pulps in different paper grades, Appita 31(5), 365370.

González, I., Sami, B., Pélach, M. A., Alcalá, M., Vilaseca, F. and Mutjé, P. (2012): Nanofibrillared cellulose as paper additivs in eucalyptus pulps, Bioresourses 7(4), 5167-5180.

Heijnesson-Hultén, A. (2005) Method of preparing microfibrillar polysaccharide. WO2007/001 229 A1.

Hellström, P., Heijnesson-Hultén, A., Paulsson, M., Håkansson, H., Germgård, U. (2014): The effect of Fenton chemistry on the properties of microfibrillated cellulose, Cellulose, 21,(3), 1489-1503.

Henriksson, G., Christiernin, M. and Agnemo, R. (2005): Monocomponent endoglucanase treatment increases the reactivity of softwood sulphite dissolving pulp, J. Ind. Microbiol. Biot. 32(5), 211-214.

Henniges, U., Okubayashi, S., Rosenau, T., Potthast, A. (2012): Irradiation of cellulosic pulps: Understanding its impact on cellulose oxidation, Biomacromolecules, 13, (12), 41714178.

Henriksson, M., Henriksson, G., Berglund, L. A. and Lindström, T. (2007): An environmentally friendly method for enzyme-assisted preparation of microfibrillated cellulose (MFC) nanofibers, Eur. Polym. J. 43(8), 3434-3441.

Höglund, H. (2002): Mechanical pulp fibres for new and improved paper grades, 7th Int. Conf. New Available Technol., Stockholm, Sweden, June 4-6, SPCI, Stockholm, Sweden, pp. 158-163.

Isogai, A. and Kato, Y. (1998): Preparation of polyuronic acid from cellulose by TEMPO-mediated oxidation, Cellulose 5(3), 153-164.

Isogai, A., Saito, T. and Fukuzumi, H. (2011): TEMPOoxidized cellulose nanofibers, Nanoscale 3(1), 71-85.

Iwamoto, S., Kai, W., Isogai, T., Saito, T., Isogai, A. and Iwata, T. (2010): Comparison study of TEMPO-analogous compounds on oxidation efficiency of wood cellulose for preparation of cellulose nanofibrils, Polym. Degrad. Stabil. 95(8), 1394-1398.

Joseleau, J.-P., Chevalier-Billosta, V. and Ruel, K. (2012): Interaction between microfibrillar cellulose fines and fibers: influence on pulp qualities and paper sheet properties, Cellulose 19(3), 1-9.

Kajanto, I. and Kosonen, M. (2012): The potential use of micro- and nano-fibrillated cellulose as reinforcing element in paper, J-FOR 2(6), 42-48.

Klinga, N., Sandberg, C. and Höglund, H. (2005) Sheet properties of high yield pulps related to different pressing and drying conditions, Int. Mech. Pulp. Conf., Oslo, Norway, June 79, Papperindustriens Tekniske Forening, Oslo, Norway, pp. 344-348.

Klinga, N., Höglund, H. and Sandberg, C. (2008): Energy efficient high quality CTMP for paperboard, J. Pulp Paper Sci. 34(2), 98-106.

Lavoine, N., Desloges, I., Dufresne, A. and Bras, J. (2012): Microfibrillated cellulose - Its barrier properties and applications in cellulosic materials: A review, Carbohydr. Polym. 90(2), 735764.

Mörseburg, K. and Chinga-Carrasco, G. (2009): Assessing the combined benefits of clay and nanofibrillated cellulose in layered TMP-based sheets, Cellulose 16(5), 795-806.

Osong, S. H., Norgren, S., Per, E. (2014): Paper strength improvement by inclusin of nano-ligno-cellulose to Chemitermomechanical pulp, Nordic Pulp and Paper Research Journal, 29,(2), 309-316.

Pouyet, F., Chirat, C., Potthast, A., Lachenal, D. (2014): Formation of carbonyl groups on cellulose during ozone treatment of pulp: Consequences for pulp bleaching, Carbohydr Polym, 109, (0), 85-91.

Pynnönen, T., Paltakari J. and Paulapurp, H. (2005) Improving the strength properties of high-temperature TMP and CTMP by adding fines, Int. Mech. Pulp. Conf., Oslo, Norway, June 7-9, Papperindustriens Tekniske Forening, Oslo, Norway, pp. 274-277.

Pääkkö, M., Ankerfors, M., Kosonen, H., Nykänen, A., Ahola, S., Österberg, M., Ruokolainen, J., Laine, J., Larsson, P. T., Ikkala, O. and Lindström, T. (2007): Enzymatic hydrolysis combined with mechanical shearing and high-pressure homogenization for nanoscale cellulose fibrils and strong gels, Biomacromolecules 8(6), 1934-1941.

Retulainen, E., Moss, P. and Nieminen, K. (1993): Effect of fines on the properties of fibre networks, Products of Papermaking - 10th Fund. Res. Symp., Oxford, UK, September 20-24, Pira International, Leatherhead, UK, vol. 2, pp. 727-769.

Retulainen, E. and Nieminen, K. (1996): Fibre properties as control variables in papermaking? Part 2. Strengthening interfibre bonds and reducing grammage Paperi Puu 78(5), 305-312.

Rojas, J. and Hubbe, B. (2004): The dispersong science of papermaking, J. Disper. Sci. Technol. 25(6), 713-732.

Rundlöf, M. (2002): Interaction of dissolved and colloidal substances with fines of mechanical pulp - Influence on sheet properties and basic aspects of adhesion, PhD Thesis, Royal Institute of Technology, Stockholm, Sweden. 
Sandquist, D. (2013): New horizons for microfibrillated cellulose, Appita J. 66(2), 156-162.

Syverud, K., Stenius, P. (2009): Strength and barrier properties of MFC films, Cellulose, 16,(1), 75-85.

Taipale, T., Österberg, M., Nykänen, A., Ruokolainen J. and Laine, J. (2010): Effect of microfibrillated cellulose and fines on the drainage of kraft pulp suspension and paper strength, Cellulose 17(5), 1005-1020

Tapin-Lingua, S., Meyer, V., Petit-Conil, M. J. (2013) Correlations between pulp composition and efficiency of M/NFC production. Tappi International Conference on Nano Technology for renewable Materials, Royal Institute of Technology, 24-27 June, 2013, pp, Stocjholm, Sweden.

Turbak, A. F., Snyder, F. W., Sandberg, K. R. (1983) Microfibrillated cellulose, a new cellulose product: Properties, uses, and commercial potential J Appl Polym Sci, Appl Polym Symp 37, 815-827.
Zhang, K., Fischer, S., Geissler, A. and Brendler, E. (2012): Analysis of carboxylate groups in oxidized never-dried cellulose II catalyzed by TEMPO and 4-acetamide-TEMPO, Carbohydr. Polym. 87(1), 894-900.

Zimmermann, T., Bordeanu, N., Strub, E. (2010): Properties of nanofibrillated cellulose from different raw materials and its reinforcement potential, Carbohydr Polym, 79,(4), 1086-1093.

Österberg, M. and Cranston, E. D. (2014): Special issue on nanocellulose - Editorial, Nord. Pulp Paper Res. J. 29(1), 2-3.

\section{Manuscript received July 4, 2014} Accepted September 18, 2014 